\title{
Impactos Dinâmicos dos Fatores de Produção e da Produtividade sobre a Função de Produção Agrícola
}

\author{
Cassiano Bragagnoloํㅡ e Geraldo Sant'Ana de Camargo Barros ${ }^{2}$
}

Resumo: Este trabalho tem por objetivo analisar os impactos dinâmicos dos fatores de produção capital, trabalho e terras, bem como da produtividade total dos fatores (PTF) no produto agrícola para o período 1972-2009. Os resultados indicam que à medida que a PTF cresce o trabalho diminui e que, portanto, a modernização da agricultura, ocorrida a partir dos anos 1970, trouxe inovações tecnológicas poupadoras de mão de obra. A decomposição histórica da variância dos erros de previsão do modelo indicou que durante as décadas de 1970 e 1980 o produto agrícola foi maior que o esperado e que isto só foi possível devido aos elevados ganhos de produtividade ocorridos à época. Nas décadas posteriores, embora a produtividade continuasse a elevar o potencial de crescimento do produto, fatores como baixo investimento e diminuição da expansão da fronteira agrícola limitaram o crescimento da produção, que ficou abaixo do esperado.

Palavras-chaves: Fatores de produção na agricultura, vetor autorregressivo, crescimento agrícola.

\footnotetext{
Abstract: This study analyzes the dynamic impacts of the production factors capital, labor and lands as well as total factor productivity (TFP) in agriculture economic growth for the period from 1972 to 2009. The results suggest that as the TFP increases labor decreases, and that the modernization of agriculture has brought technological innovations that uses less labor in the production process. The variance historical decomposition of forecast errors indicated that during the 1970's and 1980 's, agricultural product was larger than expected. This was only possible due to the high productivity's gains occurred at that time. During the 1990's and 2000's, while productivity continued to increase the potential

1. Professor Adjunto do Departamento de Economia da Universidade Federal de São Carlos (UFSCar) - campus Sorocaba. E-mail: cassiano@ufscar.br

2. Coordenador científico do Centro de Estudos Avançados em Economia Aplicada (Cepea)/ USP e Professor Titular do Departamento de Economia, Administração e Sociologia da Escola Superior de Agricultura "Luiz de Queiroz" da Universidade de São Paulo (Esalq)/USP. E-mail: gscbarro@usp.br
} 
output growth, factors such as low investment and decreasing land expansion limited the agricultural economic growth, which was lower than expected.

Key-words: agricultural production factors, vector autoregressive, agricultural economic growth.

Classificação JEL: Q10, C22, O40.

DOI: http://dx.doi.org/10.1590/1234-56781806-9479005301002

\section{Introdução}

Considerando-se as últimas décadas, não há dúvidas de que a agricultura brasileira alcançou ganhos elevados de produtividade. A despeito da grande relevância do tema, o papel da produtividade total dos fatores (PTF) na dinâmica da produção agrícola brasileira tem sido relativamente pouco estudado. Dentre os trabalhos que abordam o tema podem-se citar Bonelli e Fonseca (1998) e Gasques et al. (2010).

Bonelli e Fonseca (1998) estimaram a PTF para os setores industrial e agrícola tomando como base o período 1975-1996. Os autores observaram que, entre 1979 e 1984, a taxa anual de crescimento da PTF agrícola esteve ao redor de 4,5\% a $5 \%$, com exceção do ano de 1982, quando esteve próxima de 1\%. Em 1976, 1978, 1985, 1986 e 1988, a variação da PTF agrícola foi negativa. Para o período compreendido entre 1989 e 1996, a variação da PTF agrícola foi positiva, oscilando entre $1,1 \%$ e $5,0 \%$, com média de $2,9 \%$ no período.

Gasques et al. (2010) afirmaram que o aumento da produtividade foi o principal fator de estímulo ao crescimento da agricultura brasileira. Fazendo uso do índice de Tornqvist, os autores mostraram que, entre 1975 e 2008, o índice do produto da agropecuária passou de 100 para 366, enquanto o índice dos insumos passou de 100 para 107. Os autores argumentaram que esses números refletem um crescimento baseado essencialmente nos ganhos de produtividade, devido à grande diferença entre o crescimento do produto e o crescimento do uso de insumos. Gasques et al. (2010) estimaram um crescimento da PTF para o período compreendido entre 1975 e 2008 de $3,68 \%$ ao ano.

Poucos trabalhos, entretanto, buscam analisar os efeitos dinâmicos entre as variáveis que afetam o produto agrícola e o papel da PTF neste contexto. Desta forma, este trabalho tem por objetivo analisar os impactos dinâmicos das séries históricas dos fatores de produção capital, trabalho e terras, bem como da PTF, na série histórica do produto agrícola - excluindo-se a produção pecuária e florestal - simulando uma função de produção agrícola e utilizando uma estratégia empírica baseada em um modelo econométrico VAR estrutural com dados para o período 1972-2009. À luz da metodologia proposta é possível avaliar os impactos dos choques de PTF sobre as demais variáveis - capital, trabalho, terras e produto agrícola - e de choques nos fatores de produção e na PTF sobre o produto agrícola. Além disso, por se tratar de um modelo de previsão, se torna possível comparar os resultados previstos por meio do modelo com os observados para o produto e calcular a contribuição de cada uma das variáveis para o erro de previsão da série histórica de produto, bem como relacionar os resultados com as transformações ocorridas na agricultura brasileira no período. 
O trabalho está dividido em seis seções. $\mathrm{Na}$ próxima seção realizar-se-á uma breve revisão bibliográfica, visando apresentar com mais detalhes o problema de pesquisa. Na terceira seção desenvolver-se-á uma breve exposição do modelo econométrico VAR estrutural utilizado, seguido, na seção 4, de uma apresentação da base de dados utilizada. Na quinta seção apresentam-se os resultados e discussão e, por fim, na seção 6 são apresentadas as conclusões.

\section{Revisão bibliográfica}

A agricultura teve, historicamente, função relevante no crescimento econômico brasileiro. Este fato não foi uma particularidade brasileira. De acordo com Jorgenson (1961), no processo de desenvolvimento econômico de diversos países a agricultura foi importante como fornecedora de recursos para investimentos em atividades emergentes, para a liberação de mão de obra para outros setores, como provedora de poupança para a acumulação de capital, bem como devido à oferta de alimentos a preços acessíveis para a população.

Na década de 1950, a política agrícola brasileira teve foco na expansão da fronteira agrícola e, por consequência, no aumento da produção de alimentos. De acordo com Barros et al. (1977), este processo baseou-se, principalmente, na melhoria da infraestrutura de comercialização de produtos agropecuários, por meio de investimentos públicos em transporte e armazenamento. $\mathrm{O}$ abastecimento alimentar foi garantido e a principal fonte de crescimento da agricultura, de acordo com os autores, esteve relacionada à elevação substancial do contingente de mão de obra e da incorporação de novas terras ao processo produtivo.

Na década de 1960, a agricultura já desempenhava o papel de contribuir no processo de estabilização da economia brasileira, devido aos sérios problemas de equilíbrio interno (inflação) e externo (balanço de pagamentos) do período. Além disso, Barros (1979) afirmou que, no período, recursos foram transferidos da agricultura para a indústria nacional. Desta forma, a agricultura teria contribuído significativamente para o crescimento da indústria no País.

Durante a década de 1960 ocorreu, ainda, a implantação do regime militar no País, com importantes mudanças na economia brasileira. Este regime tirou a prioridade da reforma agrária e introduziu um modelo que tinha como base a modernização da agricultura. Para Barros (1982), este processo de modernização da agricultura teve como base quatro pontos principais: maior abertura ao comércio internacional; forte expansão dos programas de crédito rural subsidiado; aumento dos gastos com pesquisa e extensão rural; especial tratamento ao setor de insumos e fatores de produção (tratores, fertilizantes, inseticidas e herbicidas).

O governo, prevendo a necessidade de investimento que a modernização da agricultura iria exigir, assumiu a responsabilidade de financiar este processo, implementando, em 1965, o chamado Sistema Nacional de Crédito Rural (SNCR). De acordo com Alves e Araújo (2002), no caso da agricultura brasileira, a disponibilidade de crédito público abundante, que foi elemento característico durante as décadas de 1960, 1970 e 1980, teria afetado a decisão de investimento dos agricultores.

Assim, o crédito rural, ao prover recursos subsidiados para compra de insumos e maquinário, foi o principal instrumento de modernização da agricultura nos anos 1960 e 1970 (OLIVEIRA; MONTEZANO, 1982). Em paralelo, o governo implementou a Política de Garantia de Preços Mínimos (PGPM), que cuidou da sustentação de preços agrícolas e da formação de estoques reguladores, com os programas de Aquisição do Governo Federal (AGF) e Empréstimos do Governo Federal (EGF). Ademais, os anos 1970 repercutiram internamente elevações mundiais nos preços agropecuários, em especial dos alimentos.

Santos (1984) concluiu que os preços relativos entre os produtos e os fatores de produção favoreceram a incorporação das novas tecnologias nas décadas de 1960 e 1970. De acordo com Rezende 
(2006), como o capital era subsidiado, enquanto a legislação trabalhista e agrária elevava o custo da mão da obra, a tecnologia tinha o condão de intensificar a mecanização e a ocupação de novas áreas, que, principalmente no caso do Cerrado, demanda tecnologia especial para agricultura tropical. Este papel de desenvolvimento tecnológico seria cumprido com excelência pela Embrapa.

Os efeitos da modernização podem ser observados nos dados apresentados na Tabela 1. A relação do número de hectares por trator de rodas correspondia a 2.281 em 1950, e 468 em 1960. Este valor reduziu-se durante as décadas de 1960, 1970 e 1980 até estabilizar-se nas décadas mais recentes. Os índices de área por trator indicam uma nova dinâmica para a agricultura no período e o consequente sucesso dos esforços de modernização da agricultura brasileira.

A Figura 1 apresenta o índice do número de tratores de rodas comercializados no período 1970-2010. Pode-se perceber que os maiores índices de investimentos em tratores ocorreram durante a década de 1970. Estes índices reduzem-se ao longo das décadas de 1980 para atingirem

Tabela 1. Índice de mecanização da agricultura brasileira (1950 a 2006)

\begin{tabular}{cccc}
\hline Período & $\begin{array}{c}\text { Número de tratores } \\
\text { (em unidade) }\end{array}$ & $\begin{array}{c}\text { Área cultivada } \\
\text { (em mil ha) }\end{array}$ & $\begin{array}{c}\text { Área por trator } \\
\text { (em ha/unidade) }\end{array}$ \\
\hline 1950 & 8.372 & 19.095 & $2.280,8$ \\
1960 & 61.345 & 28.712 & 468,0 \\
1970 & 165.870 & 33.983 & 204,9 \\
1975 & 323.113 & 42.208 & 130,6 \\
1980 & 545.205 & 57.726 & 105,9 \\
1985 & 665.280 & 62.809 & 94,4 \\
1995 & 799.742 & 50.104 & 62,7 \\
2006 & 820.673 & 59.843 & 72,9 \\
\hline
\end{tabular}

Fonte: Censos Agropecuários do Instituto Brasileiro de Geografia e Estatística.

Figura 1. Evolução do índice do número de tratores de rodas comercializados (1970=1) - anual (1970 a 2010$)$

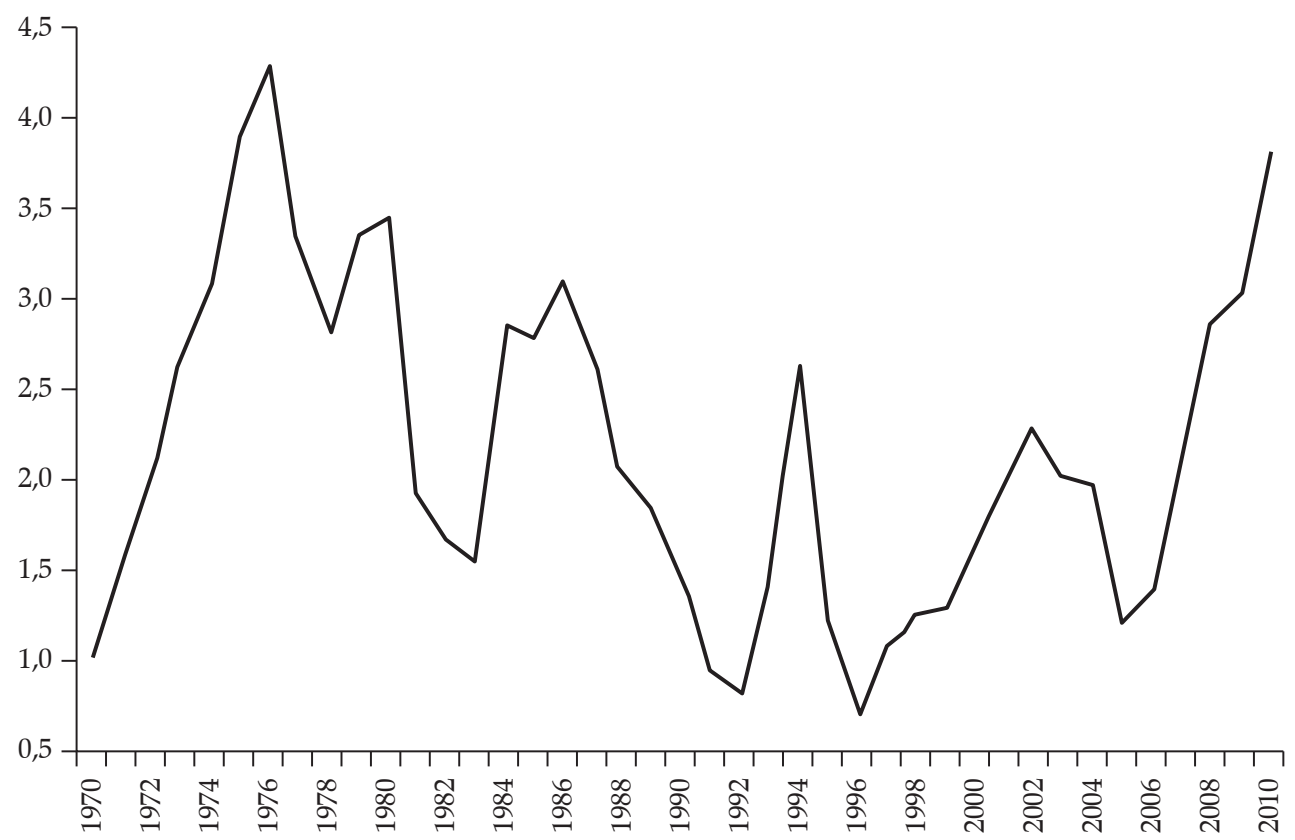

Fonte: Associação Nacional dos Fabricantes de Veículos Automotores. 
seus menores valores na década de 1990. A partir de meados da década de 1990 até os anos 2000, existe uma recuperação dos índices de investimento em tratores que voltam a apresentar valores elevados nos anos mais recentes.

Este menor nível de investimento em tratores, ocorrido ao longo da década de 1990, levou a um envelhecimento médio da frota. Desta forma, embora tenha havido aumento no índice de mecanização no período e no número total de tratores, ocorreu, também, depreciação da frota de tratores devido à redução no ritmo de investimento em tratores novos e consequente grande número de tratores antigos compondo a frota total, havendo redução no estoque de tratores disponíveis em termos monetários (BARROS, 1999).

No que tange a utilização da mão de obra agrícola, Johnson (1950) afirmou que esta varia pouco ao longo do tempo. Para tanto, o autor parte da constatação que o montante de trabalhadores assalariados empregados na produção agrícola não oscilou significativamente ao longo da Grande Depressão nos Estados Unidos e que mesmo a parte não fixa da mão de obra, composta pela mão de obra temporária, tendeu a ser plenamente empregada (BARROS, 1999).

A Tabela 2 apresenta a evolução do pessoal ocupado na agricultura divididos em pessoas com e sem laço de parentesco com o produtor. O total de pessoal ocupado aumentou até 1985, caindo, a seguir, para um nível próximo ao de 1970 ao longo dos anos 2000. Porém, fica claro que a ocupação de mão de obra esteve muito aquém da utilização de capital - com o estoque de tratores multiplicando-se por cinco (conforme pode ser visto na Tabela 1) - no mesmo período, caracterizando-se a substituição entre esses fatores a favor da mecanização. Pode-se perceber que a participação da mão de obra familiar no total de pessoas ocupadas tem oscilado entre $70 \%$ e $80 \%$ nas últimas décadas. A grande participação de produtores no total de pessoas ocupadas na agricultura corrobora com a ideia de estabilidade do nível de emprego na agricultura brasileira, uma vez que existem poucos trabalhadores contratados para realizar os ajustes necessários de mão de obra. Desta forma, uma possível diminuição de trabalho na função de produção agrícola poderia se dar através da redução do número de horas trabalhadas no âmbito da mão de obra familiar, ou, no limite, através da migração para o meio urbano.

Ao longo dos anos 1980, dado o endividamento público elevado, o uso mais restrito de recursos fiscais levou o governo a reduzir seu grau de intervenção na economia. Ademais, a preocupação com a crescente inflação reduzia também o espaço para política de crédito subsidiado. As dificuldades agravaram-se ainda mais, visto que nos anos 1980 observou-se também acentuada queda dos preços internacionais agropecuários, fruto da elevação dos juros e da guerra dos subsídios entre os Estados Unidos e a Comunidade Europeia (ANDERSON, 2010). Essa soma de fatores adversos iria tornar essencial um salto de produtividade para que a competitividade da agricultura brasileira fosse mantida.

Tabela 2. Número e percentual de pessoal ocupado nos estabelecimentos com e sem laço de parentesco com o produtor (1970 a 2006)

\begin{tabular}{|c|c|c|c|c|c|}
\hline \multirow{2}{*}{ Ano } & \multicolumn{2}{|l|}{ Mão de obra familiar } & \multicolumn{2}{|l|}{ Mão de obra contratada } & \multirow{2}{*}{ Total } \\
\hline & Número de pessoas ocupadas & $\%$ & Número de pessoas ocupadas & $\%$ & \\
\hline 1970 & 14.096 .417 & 80,2 & 3.471 .463 & 19,8 & 17.567 .880 \\
\hline 1975 & 16.374 .434 & 80,5 & 3.971 .242 & 19,5 & 20.345 .676 \\
\hline 1980 & 15.642 .854 & 73,9 & 5.520 .875 & 26,1 & 21.163 .729 \\
\hline 1985 & 17.640 .732 & 75,4 & 5.754 .149 & 24,6 & 23.394 .876 \\
\hline 1995 & 13.607 .876 & 75,9 & 4.322 .977 & 24,1 & 17.930 .853 \\
\hline 2006 & 12.801 .179 & 77,3 & 3.766 .365 & 22,7 & 16.567 .544 \\
\hline
\end{tabular}

Fonte: Censos Agropecuários do Instituto Brasileiro de Geografia e Estatística. 
Os anos 1990 foram caracterizados pelo reduzido volume de crédito, sendo que o aporte de recursos fiscais limitava-se à equalização das taxas de juros oficiais. Novas formas de financiamento com mais envolvimento do mercado foram se desenvolvendo, como a Cédula de Produto Rural (CPR) e variadas formas de mercado a termo com adiantamento de recursos pelas empresas do agronegócio, seja na forma de insumos ou de dinheiro.

Também no início dos anos 1990, ocorreu uma mudança de orientação do modelo de desenvolvimento econômico. A economia brasileira, que era bastante fechada, tornou-se gradualmente mais aberta ao comércio internacional. Esperava-se que, com essa abertura, ocorressem duas mudanças (MELO, 2002):

1. redução das tarifas de importação e, consequentemente, desvalorização da taxa de câmbio, levando a um aumento do preço relativo dos produtos, principalmente de exportação;

2. redução das tarifas de importação dos fatores de produção e insumos agrícolas (fertilizantes, defensivos, medicamentos, máquinas etc.), o que provocaria diminuições de preços internos.

De acordo com Melo (2002), essas duas consequências da abertura comercial aumentariam a lucratividade do setor agrícola, entretanto, o autor argumenta que ocorreu o oposto, havendo redução dos preços reais causada pela valorização da taxa de câmbio.

Silva (1995) destaca que a valorização da taxa de câmbio ocorreu a partir do surgimento do Plano Real em 1994. O plano visava controlar a inflação e foi caracterizado pela política monetária restritiva e pela âncora cambial. Silva (1995) destaca, ainda, que estas políticas resultaram em expressivo crescimento das dívidas externa e interna.

Os anos 1990 ficaram marcados também pela inserção da agricultura brasileira no processo de globalização, o que viria a ser acelerado ao longo da década de 2000. Isso significava que aumentos de produção fundados na produtividade encontrariam mercados internacionais em expansão, com preços relativamente estáveis.

Melo (1998) afirmou que o aumento da produtividade ocorrido durante a década de 1990 pode ser considerado uma compensação a uma conjuntura macroeconômica desfavorável para a agricultura, com juros altos e taxa de câmbio sobrevalorizada.

Mendes, Teixeira e Salvato (2009) verificaram os efeitos dos investimentos em infraestrutura na PTF do setor agropecuário brasileiro, no período de 1985 a 2004, incorporando variáveis como investimentos em telecomunicações, pesquisa (P\&D) e armazenagem. Os autores determinaram, também, a defasagem de tempo entre os investimentos e os seus efeitos na PTF e analisaram o sentido de causalidade entre a PTF e esses investimentos, por meio do Método Generalizado de Momentos (GMM). Os principais resultados encontrados mostraram que um aumento de $1 \%$ nos investimentos em rodovia aumenta a PTF, em média, $0,72 \%$, com o tempo médio de defasagem de um ano. $\mathrm{O}$ aumento de $1 \%$ em pesquisa aumenta a PTF, em média, $0,43 \%$, sendo que o retorno acontece no mesmo ano. Um aumento de $1 \%$ nos investimentos na relação entre área irrigada e área plantada aumenta a PTF, em média, $0,20 \%$. Além disso, os autores constatam que um aumento de $1 \%$ nos investimentos no setor de energia elétrica aumenta a PTF, $0,15 \%$ com tempo de defasagem de dois anos.

Adicionalmente, destaca-se que o crescimento de produção experimentado pela agricultura foi motivado apenas em parte pelo aumento da área cultivada. Na Figura 2 pode-se perceber que existe tendência de aumento do valor bruto da produção (VBP), ao passo que a área colhida manteve um crescimento significativo, porém bastante inferior ao do produto.

Brandão, Rezende e Marques (2005) analisaram o crescimento agrícola brasileiro após a mudança da política cambial, em janeiro de 1999. Os autores tomaram como base o comportamento da taxa de câmbio e dos preços internacionais das commodities ao longo do período 1999/2004 e dis- 
Figura 2. Evolução dos Índices de valor bruto da produção $(\mathrm{VBP})^{1} \mathrm{e}$ área colhida ${ }^{2}(1970=1)$ - anual (1970 a 2008)

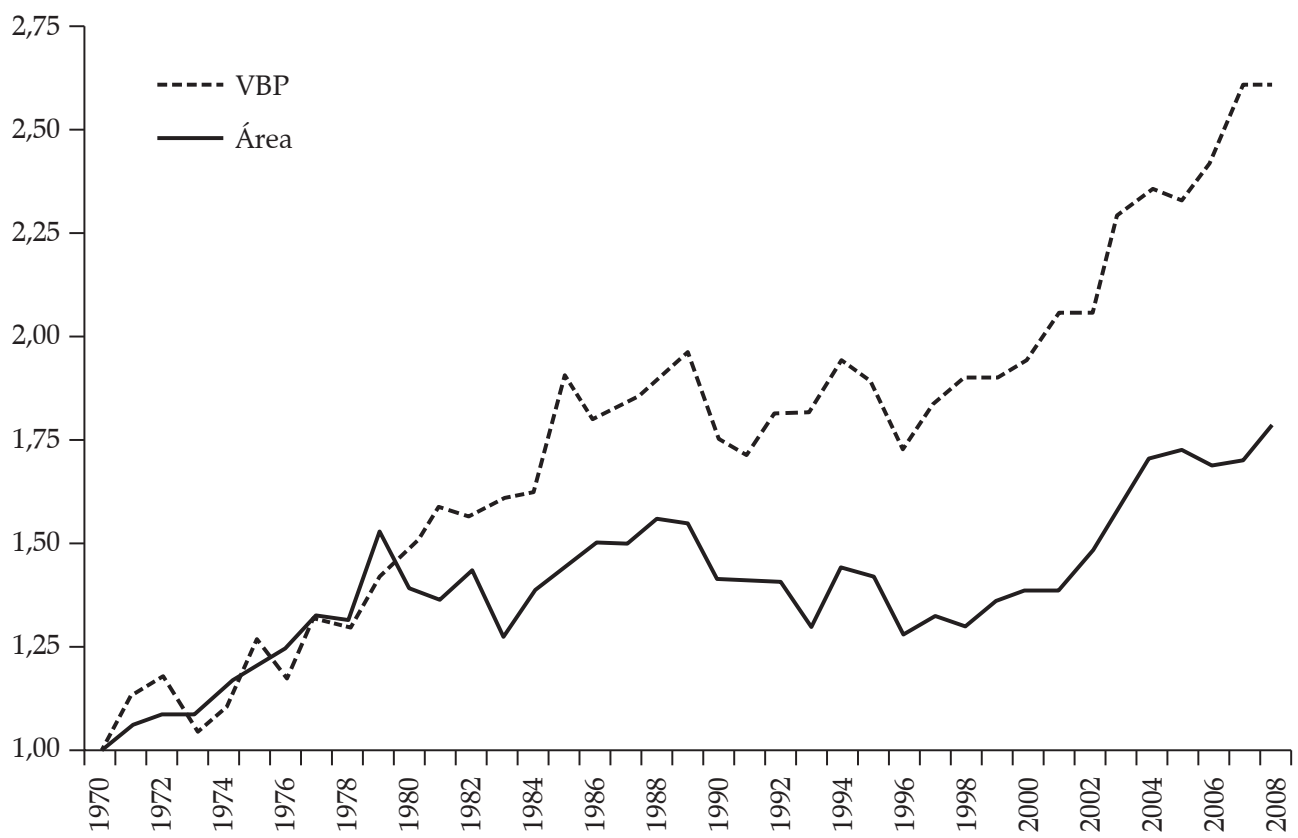

Fonte: Fundação Instituto Brasileiro de Geografia e Estatística e Fundação Getúlio Vargas.

cutiram também o comportamento da área cultivada com soja nesse período. Propuseram que a expansão da área cultivada desta cultura poderia sugerir que a agricultura brasileira tivesse voltado a crescer devido a aumentos de área plantada. Entretanto, os autores sugeriram que essa expansão de área cultivada se deu, preponderantemente, no âmbito de áreas de pastagens degradadas, que encontraram na sua conversão temporária à soja a maneira mais adequada de se renovarem.

\section{Modelo econométrico}

Os procedimentos econométricos adotados foram testes de raiz unitária e um modelo de Vetor Autorregressivo (VAR) estrutural. O VAR estrutural compreende a estimação da função de impulso resposta e a análise da decomposição histórica da variância. O modelo VAR estrutural é calculado a fim de estimar o impacto das variáveis selecionadas sobre o produto agrícola.
Sob estas condições é possível realizar uma análise econômica impondo uma quantidade mínima de restrições que são consistentes com um conjunto de modelos teóricos visando identificar choques estruturais, construir funções de impulso resposta e obter a decomposição histórica da variância (CANOVA, 2007).

O sistema VAR estrutural proposto para a função de produção da agricultura brasileira envolve as variáveis PTF, trabalho, capital, terra e produto com informações anuais para o período compreendido entre 1972 e 2009. Os dados entraram no cálculo do modelo VAR estrutural em logaritmos.

Foi considerado o seguinte sistema (ENDERS, 2004):

$$
\mathrm{A}_{0} \mathrm{X}_{\mathrm{t}}=\mathrm{a}+\sum_{\mathrm{i}=1}^{\mathrm{p}} \mathrm{A}_{\mathrm{i}} \mathrm{x}_{\mathrm{t}-\mathrm{i}}+\varepsilon_{\mathrm{t}}
$$

em que: $A_{0}(5 \times 5)$ é uma matriz de relações contemporâneas entre as cinco variáveis endógenas $\left(x_{t}\right)$ e o vetor $\varepsilon_{t}(5 \times 1)$ representa os erros não correlacionados do modelo. 
Conforme o modelo econômico proposto, define-se:

$$
x_{t}=\left[p_{t}, H_{t}, K_{t}, T_{t}, Y_{t}\right]
$$

e

$$
\mathrm{A}_{0}=\left[\begin{array}{ccccc}
1 & 0 & 0 & 0 & 0 \\
0 & 1 & 0 & 0 & 0 \\
0 & 0 & 1 & 0 & 0 \\
0 & 0 & 0 & 1 & 0 \\
a_{51} & a_{52} & a_{53} & a_{54} & 1
\end{array}\right]
$$

sendo: P a PTF, H o número de horas trabalhadas na agricultura, $\mathrm{K}$ o capital agrícola, $\mathrm{T}$ a área colhida e $\mathrm{Y}$ o produto agrícola.

Quando verificada a existência de cointegração entre as variáveis, o termo de correção do erro é introduzido no modelo VAR. Da eq. (1), obtém-se (ENDERS, 2004):

$$
\mathrm{x}_{\mathrm{t}}=\mathrm{A}_{0}^{-1} \mathrm{a}+\sum_{\mathrm{i}=1}^{\mathrm{p}} \mathrm{A}_{0}^{-1} \mathrm{~A}_{\mathrm{i}} \mathrm{x}_{\mathrm{t}-1}+\mathrm{A}_{0}^{-1} \varepsilon_{\mathrm{t}}
$$

ou,

$$
x_{t}=\beta_{0}+\sum_{i-1}^{p} \beta_{1} x_{t-1}+e_{t}
$$

Sob condições de estabilidade, tem-se que (ENDERS, 2004):

$$
\mathrm{x}_{\mathrm{t}}=\mu+\sum_{\mathrm{i}=0}^{\infty} \phi_{\mathrm{i}} \varepsilon_{\mathrm{t}-\mathrm{i}}
$$

De acordo com Enders (2004), caso o sistema obtido a partir da eq. (1) seja sobreidentificado, considerando $\mathrm{A}_{0}$, utiliza-se um processo conhecido como Método Generalizado de Momentos (GMM):

1. Estima-se o VAR definido pela eq. (2);

2. Obtém-se a matriz de variância e covariância $\Sigma_{\mathrm{e}}$ e calcula-se $\Sigma_{\varepsilon}=\mathrm{A}_{0} \Sigma_{\mathrm{e}} \mathrm{A}_{0}^{\prime}$;

3. Maximiza-se a seguinte função de verossimilhança:

$$
-\frac{\mathrm{T}}{2} \ln \left|\mathrm{A}_{0}^{-1} \Sigma_{\varepsilon}\left(\mathrm{A}_{0}^{\prime}\right)^{-1}\right|-\frac{1}{2} \sum_{\mathrm{t}=1}^{\mathrm{T}}\left(\hat{\mathrm{e}}_{\mathrm{t}} \mathrm{A}_{0}^{\prime} \Sigma_{\varepsilon}^{-1} \mathrm{~A}_{0} \hat{\mathrm{e}}_{\mathrm{t}}\right)
$$

Com o procedimento proposto, espera-se que o capital, a área plantada, o número de horas tra- balhadas e a PTF expliquem de forma satisfatória o produto agrícola. Além disso, espera-se, ainda, que variações na PTF tenham alguma influência sobre a utilização dos insumos.

O teste utilizado para se determinar a existência de raiz unitária nas séries foi o desenvolvido por Elliott, Rothenberg e Stock (1996), conhecido como DF-GLS. De acordo com Pfaff (2008), testes de estacionariedade como o Dickey-Fuller aumentado (ADF) podem falhar caso o processo gerador de dados seja um AR(1) com coeficiente próximo a um. Elliott, Rothenberg e Stock (1996) desenvolveram um teste para corrigir esta deficiência. O teste proposto pelos autores é o chamado DF-GLS e consiste em um teste do tipo ADF modificado. As eq. (4) e (5), a seguir, são utilizadas para o processo gerador de dados da série $\mathrm{y}_{1}, \ldots, \mathrm{y}_{\mathrm{T}}$ :

$$
\begin{aligned}
& \mathrm{y}_{\mathrm{t}}=\mathrm{d}_{\mathrm{t}}+\mathrm{u}_{\mathrm{t}} \\
& \mathrm{u}_{\mathrm{t}}=\mathrm{au}_{\mathrm{t}}+\mathrm{v}_{\mathrm{t}}
\end{aligned}
$$

em que: $d_{t}=\beta^{\prime} z_{t}$ é um componente determinístico, ou seja, uma tendência linear incluída no vetor $\mathrm{z}_{\mathrm{t}}(\mathrm{q} \times 1)$ e $\mathrm{v}_{\mathrm{t}}$ é um erro com média zero. No caso em que $a=1$, as eq. (4) e (5) implicam em integração de ordem $\mathrm{I}(1)$ para $\mathrm{y}_{\mathrm{t}}$, e no caso em que $|\mathrm{a}|<1$, o processo é estacionário.

\section{Base de dados}

Devido à limitada disponibilidade de informações para as variáveis de interesse da pesquisa, foram utilizados dados anuais para o período compreendido entre os anos de 1972 e 2009.

Conforme já mencionado, as variáveis foram selecionadas com base em uma função de produção para o produto agrícola com os fatores de produção terra, capital e trabalho, além da PTF. Como não existe uma série de estoque de capital agrícola, utilizou-se - como em Gasques et al. (2004) - uma proxy calculada com base no valor do estoque de tratores agrícolas. Para a variável terra, utilizou-se a área colhida, e para o trabalho, o número de horas trabalhadas na agricultura. A 
PTF foi calculada com base nas estimativas feitas em Bragagnolo, Spolador e Barros (2012).

A seguir descrevem-se brevemente as fontes de dados consultadas e os procedimentos adotados para a obtenção das variáveis que fazem parte do cálculo do modelo VAR estrutural proposto.

\subsection{Número de horas trabalhadas na agricultura}

O número de horas trabalhadas total na agricultura foi obtido através da multiplicação do montante de trabalhadores pelo número de horas habitualmente trabalhadas por semana, ambas obtidas a partir da Pesquisa Nacional de Amostragem Domiciliar (PNAD) e dos censos divulgados pelo Instituto Brasileiro de Geografia e Estatística (IBGE).

Para obter o montante de trabalhadores na agricultura utilizaram-se os valores correspondentes ao número de trabalhadores com ocupação principal em atividade agrícola com carga horária superior a 14 horas. Utilizou-se esta abordagem devido à descontinuidade na forma de medição do número total de trabalhadores da agricultura ${ }^{3}$.

Para obter o número de horas trabalhadas por pessoa ocupada tomaram-se as tabelas divulgadas pela PNAD que apresentam o número de pessoas ocupadas, por grupos de horas habitualmente trabalhadas por semana no trabalho principal, para o ramo de atividades agrícolas. A partir destes dados obteve-se uma média ponderada para três faixas de horas trabalhadas, calculada na quantidade média de horas trabalhadas para a faixa central (44 horas) e através dos valores extremos para as outras duas faixas (39 e 49

3. Houve mudança no método de cálculo do total de pessoal ocupado na agricultura a partir de 1992, quando começaram a ser computadas todas as pessoas que se localizassem na agricultura, incluindo produção para autoconsumo e os que exercessem trabalho agrícola não remunerado por menos de 14 horas. A utilização desta série levaria a uma elevação súbita a partir de 1992. Para corrigir o problema continuou-se a série anterior a 1992 com os valores correspondentes à mão de obra com ocupação principal em atividade agrícola e com carga horária de trabalho superior a 14 horas. horas) ${ }^{4}$. Com este procedimento, foi possível calcular um índice de horas trabalhadas médias por pessoa para cada ano da pesquisa.

\subsection{Produto agrícola}

Para obter o produto agrícola, multiplicou-se a quantidade colhida de 18 produtos agrícolas pelos seus preços médios no período 1972-2009, descontando-se a seguir os gastos com insumos agrícolas.

Os dados de produção agrícola foram obtidos a partir do Levantamento Sistemático da Produção Agropecuária (LSPA), disponibilizado pela Pesquisa Agropecuária Municipal (PAM), realizada pelo IBGE. Estes 18 produtos utilizados para o cálculo do produto representam $94 \%$ da área total colhida no período ${ }^{5}$. Os preços dos produtos empregados no cálculo foram os divulgados pela Conjuntura Econômica, da Fundação Getúlio Vargas (FGV). Estes preços foram deflacionados pelo IGP-DI para o ano de 2009, utilizando-se para o cálculo a média dos preços deflacionados para o período 1972-2009.

No cálculo das despesas com insumos partiu-se do valor apresentado no Censo Agropecuário do IBGE de 1970, considerando-se os gastos com adubos, corretivos, sementes, mudas, agroquímicos e combustíveis e deflacionando-os para 2009 por meio do IGP-DI. A partir desta medida inicial foram utilizadas as variações no uso de insumo apresentadas por Gasques et. al. (2010) para obter-se uma série de despesas que abrangesse o período de 1972 a 2009. Os valores obti-

4. Existem diferenças ao longo dos anos na forma em que a tabela de horas trabalhadas é apresentada na PNAD. As tabelas foram ajustadas para todos os anos para três faixas de horas trabalhadas: até 39 horas, 40 a 48 horas, acima de 49 horas.

5. As unidades de quantidade foram compatibilizadas com as de preços. Os produtos utilizados para o cálculo e suas respectivas unidades de mensuração foram: banana (em cacho), cacau (em kg de amêndoa), café (em kg de grão), laranja (em cento), pimenta-do-reino (em kg), algodão (em caroço), amendoim (em kg e em casca), arroz (em kg e em casca), batata-inglesa (em kg), cana-de-açúcar (em kg), cebola (em kg), feijão (em $\mathrm{kg}$ de grão), fumo (em $\mathrm{kg}$ de folha), mandioca (em ton.), milho (em kg de grão), soja (em kg de grão), tomate (em kg), e trigo (em kg de grão). 
dos com o procedimento para os anos censitários foram similares aos dos censos agropecuários dos anos de 1975, 1980, 1985, 1995 e 2006, deflacionados pelo IGP-DI e para os mesmos insumos considerados em 1970.

Com o procedimento proposto obteve-se o valor bruto da produção agrícola descontado dos gastos com insumos.

\subsection{Terras}

Para a variável terra utilizou-se a soma da área colhida dos mesmos 18 produtos selecionados no cálculo do produto agrícola. A exemplo do produto agrícola, os dados foram obtidos a partir do Levantamento Sistemático da Produção Agropecuária (LSPA), disponibilizado pela Pesquisa Agropecuária Municipal (PAM) ${ }^{6}$, realizada pelo IBGE.

\subsection{Investimento e capital agrícola}

Não existem séries disponíveis para a variável estoque de capital e investimento agrícola que contemplem o período analisado como um todo. Desta forma, o estoque de capital e os investimentos foram calculados com base no estoque de tratores, procedimento proposto por autores como Barros (1981), Barros (1999) e Alves e Araújo (2002).

Barros (1999) calcula uma proxy para as séries de capital e investimento na agricultura baseadas no estoque e nas vendas de tratores nacionais. Para obter o estoque de tratores, o autor soma 21 anos de vendas de tratores com base nos dados disponibilizados pela Associação Nacional de Fabricantes de Veículos Automotores (Anfavea). Os valores obtidos com o procedimento foram compatíveis com o número de tratores apresentados nos Censos Agropecuários de 1970, 1975, 1980, 1985 e 1995/96 e 2006.

Barros (1999), além da quantidade de tratores, utilizou uma curva teórica de depreciação

6. Dados disponíveis no Sistema Automático de Recuperação (Sidra), do IBGE. do valor dos tratores. No cálculo da curva de depreciação, estimada econometricamente com base no valor de tratores usados, o autor encontrou uma depreciação anual de 6,1\% e 6,15\% para dois modelos de trator isoladamente e 6,17\% para estes dois modelos em conjunto. Com base nos resultados encontrados, Barros (1999) sugere que a depreciação anual do estoque de tratores estaria entre $6 \%$ e $7 \%$.

O procedimento de cálculo do valor do estoque de tratores utilizado neste trabalho foi baseado na proposta de Barros (1999). A metodologia consiste em somar-se o valor atual dos tratores comercializados nos últimos 21 anos $^{7}$. Para o valor dos estoques de tratores comercializados no ano atual utilizou-se o preço dos tratores novos multiplicado pelo número de tratores comercializados no ano em questão. Para o valor no ano corrente dos tratores comercializados no ano anterior, multiplicou-se o número de tratores comercializados no ano anterior pelo preço de um novo depreciado em $6 \%$. Este procedimento foi aplicado sucessivamente até que se tivesse a soma do valor no ano atual dos tratores comercializados nos últimos 21 anos. Assim, o valor do estoque de tratores em 2009 seria composto da soma do valor no ano presente dos tratores comercializados entre 1988 e 2009, sendo que as unidades vendidas em 2009 teriam valor de um trator novo e as unidades vendidas em 1988 teriam valor bem menor, considerando-se os 21 anos de depreciação.

Os preços dos tratores novos para calcular a série de estoque de capital foram obtidos com base na média de preços de dez diferentes modelos no período entre 1999 e $2009^{8}$. Estas séries foram obtidas junto ao Departamento de Economia Rural (Deral) da Secretaria da Agricultura e

7. A evolução das vendas de tratores no Brasil é apresentada na seção 2 .

8. Os dez modelos considerados no cálculo foram: Agrale $5080.4(81 \mathrm{cv}, 4 \mathrm{X} 4)$ - Turbo, John Deere 5600 ou 5615 (75 cv, 4X2), John Deere 5700 ou $5715(85 \mathrm{cv}, 4 X 4)$, Massey Ferguson $283(86 \mathrm{cv}, 4 \mathrm{X} 4)$, Valtra $785 \mathrm{C}(75 \mathrm{cv}, 4 \mathrm{X} 4)$, Valtra BM85 (85 CV) (4X4), John Deere 6300 ou 6415 (100 cv, 4X4), John Deere 6600 ou 6615 (121 cv, 4X4), Massey Ferguson 299 (130 cv, 4X4), New Holland 7630 S100 (103 cv, 4X4). 
Abastecimento do Estado do Paraná (Seab/PR) 9 . A depreciação considerada para o valor do estoque de tratores foi de $6 \%$ ao ano, baseada na proposta de Barros (1999).

\subsection{Produtividade total dos fatores}

A PTF foi medida por meio da função proposta por Pires e Garcia (2004), tendo sido relatado em Bragagnolo, Spolador e Barros (2012). Para isso, assumiu-se que a fronteira estocástica da agricultura brasileira pode ser descrita pela eq. (4):

$$
y=f(t, x, \beta) \exp (v) \exp (-u)
$$

em que: $y$ é o vetor de produto agrícola para todos os estados brasileiros, $\mathrm{x}$ é o vetor de fatores de produção, composto por trabalho (L), capital (K) e terra (T), $\beta$ é o vetor de parâmetros e t é o tempo. Os termos v e u representam diferentes componentes de erros. Para estes erros, assume-se que $\mathrm{v} \sim \mathrm{N}\left(0, \sigma^{2}\right)$ e $\mathrm{u} \sim \mathrm{NT}\left(\mu, \sigma^{2}\right)$, sendo que a distribuição dos erros u é normal truncada.

Da parte determinística da eq. (4) pode-se obter:

$\frac{\dot{\mathrm{y}}}{\mathrm{y}}=\frac{\partial \ln \mathrm{f}(\mathrm{t}, \mathrm{K}, \mathrm{L}, \mathrm{T}, \beta)}{\partial \mathrm{t}}+\varepsilon_{\mathrm{K}} \frac{\dot{\mathrm{K}}}{\mathrm{K}}+\varepsilon_{\mathrm{L}} \frac{\dot{\mathrm{L}}}{\mathrm{L}}+\varepsilon_{\mathrm{T}} \frac{\dot{\mathrm{T}}}{\mathrm{T}}-\frac{\partial \mathrm{u}}{\partial \mathrm{t}}$

em que: $\varepsilon_{\mathrm{K}}, \varepsilon_{\mathrm{L}}$ e $\varepsilon_{\mathrm{T}}$ são as elasticidades do produto. Considerando-se que o retorno à escala (RTS) é dado por RTS $=\varepsilon_{\mathrm{K}}+\varepsilon_{\mathrm{L}}+\varepsilon_{\mathrm{T}}$, define-se que $\lambda_{\mathrm{K}}=\frac{\varepsilon_{\mathrm{K}}}{\mathrm{RTS}}, \lambda_{\mathrm{L}}=\frac{\varepsilon_{\mathrm{L}}}{\mathrm{RTS}}, \lambda_{\mathrm{T}}=\frac{\varepsilon_{\mathrm{T}}}{\mathrm{RTS}}$.

Pires e Garcia (2004) apresentam um índice para a taxa de crescimento da PTF determinado pela eq. (5):

$$
\mathrm{g}_{\text {TFP }}=\frac{\dot{\mathrm{y}}}{\mathrm{y}}-\mathrm{S}_{\mathrm{K}} \frac{\dot{\mathrm{K}}}{\mathrm{K}}-\mathrm{S}_{\mathrm{L}} \frac{\dot{\mathrm{L}}}{\mathrm{L}}-\mathrm{S}_{\mathrm{T}} \frac{\dot{\mathrm{T}}}{\mathrm{T}}
$$

em que: $S_{K}, S_{L}$ e $S_{T}$ são as parcelas dos fatores de produção capital, trabalho e terra na renda.

9. Foram utilizados preços de tratores novos referentes ao estado do Paraná. O procedimento adotado considera, portanto, que o preço de tratores no Paraná representa a média dos preços dos tratores comercializados no Brasil.
Com alguma manipulação algébrica das eq. (5) e (6), pode-se reescrever a taxa de variação da PTF de acordo com a eq. (7) a seguir:

$$
\begin{aligned}
& \mathrm{g}_{\mathrm{TFP}}=\mathrm{TP}-\dot{\mathrm{u}}+(\mathrm{RTS}-1)\left[\lambda_{\mathrm{K}} \mathrm{g}_{\mathrm{K}}+\lambda_{\mathrm{L}} \mathrm{g}_{\mathrm{L}}+\lambda_{\mathrm{T}} \mathrm{g}_{\mathrm{T}}\right] \\
& +\left[\left(\lambda_{\mathrm{K}}-\mathrm{S}_{\mathrm{K}}\right) \mathrm{g}_{\mathrm{K}}+\left(\lambda_{\mathrm{L}}-\mathrm{S}_{\mathrm{L}}\right) \mathrm{g}_{\mathrm{L}}+\left(\lambda_{\mathrm{T}}-\mathrm{S}_{\mathrm{T}}\right) \mathrm{g}_{\mathrm{T}}\right]
\end{aligned}
$$

em que: $\mathrm{TP}=\frac{\partial \ln \mathrm{f}(\mathrm{t}, \mathrm{K}, \mathrm{L}, \mathrm{T}, \beta)}{\partial \mathrm{t}}$ é o progresso técnico, ù é a mudança da eficiência técnica, $\left(\right.$ RTS - 1) $\left[\lambda_{K} g_{K}+\lambda_{L} g_{L}+\lambda_{\mathrm{T}} g_{T}\right]$ é a mudança de escala da produção e $\left[\left(\lambda_{K}-S_{K}\right) g_{K}+\left(\lambda_{L}-S_{L}\right) g_{L}+\right.$ $\left(\lambda_{\mathrm{T}}-S_{\mathrm{T}}\right) \mathrm{g}_{\mathrm{T}}$ ] é a mudança na eficiência alocativa.

Por meio da eq. (7) calculou-se a variação da PTF com base nas séries de dados apresentadas nesta seção e nos resultados obtidos no cálculo da função de produção de Bragagnolo, Spolador e Barros (2012), acumulando-se, em seguida, estas variações para obter a PTF em índice. Os resultados obtidos com o procedimento são apresentados na Figura $3^{10}$, a seguir.

\section{Resultados e discussão}

Nesta seção descrevem-se inicialmente os resultados dos testes de raiz unitária, depois são discutidos os resultados dos testes de cointegração. Na sequência, são analisados os coeficientes da matriz $\mathrm{A}_{0}$, a decomposição dos erros de previsão e as funções de impulso resposta. Por fim, analisa-se a decomposição histórica da variância dos erros de previsão do modelo.

Na Tabela 3, são apresentados os resultados dos testes DF-GLS com e sem inclusão de tendência, nos quais a hipótese nula é de presença de raiz unitária.

10. Utilizou-se o valor do estoque de tratores (em R\$), o número de trabalhadores, a área colhida (em ha) e o valor bruto da produção (em R\$). As participações do capital, do trabalho e da terra no produto foram os mesmos apresentados por Bragagnolo, Spolador e Barros (2010). 
Figura 3. Produtividade total dos fatores agrícola - Índice (1972 = 1) - anual (1972 a 2009)

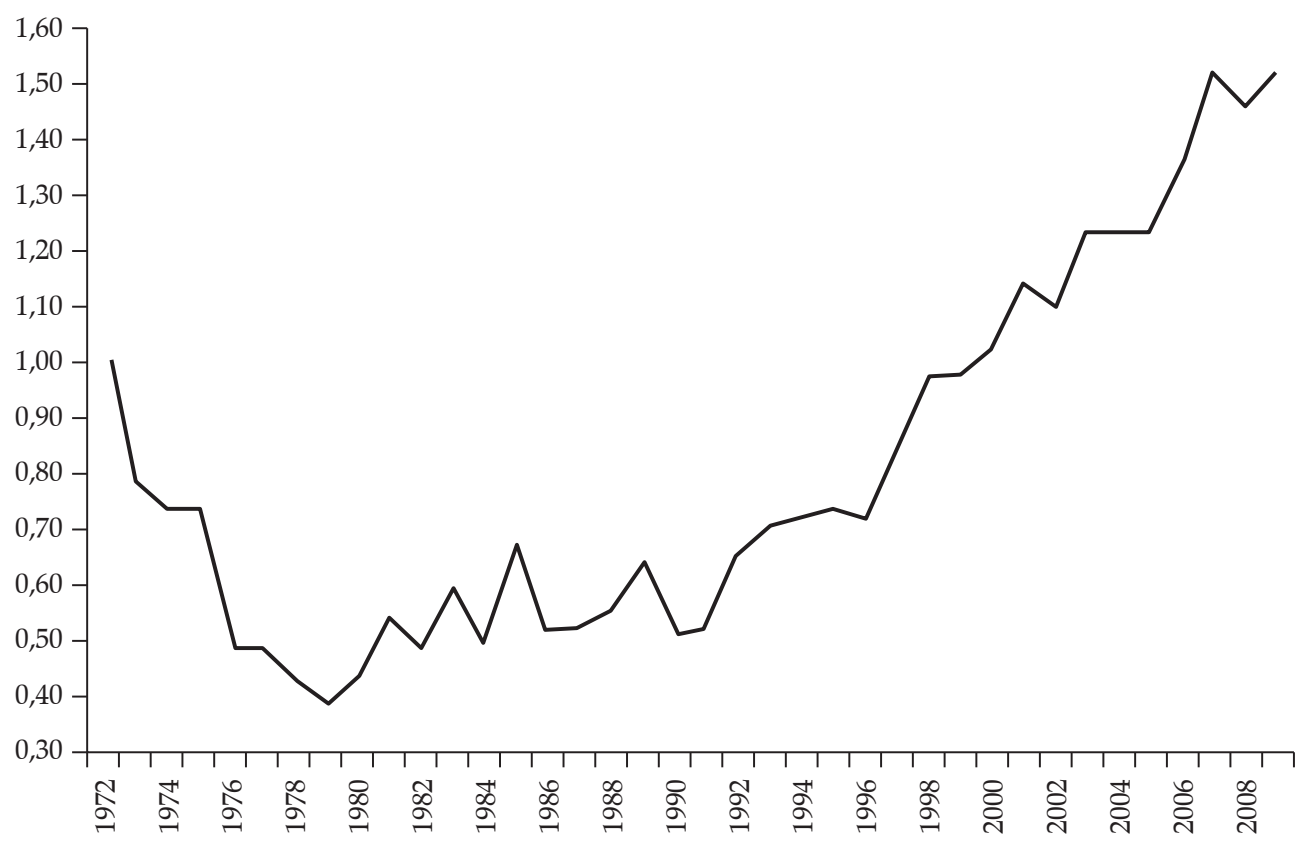

Fonte: Fundação Instituto Brasileiro de Geografia e Estatística - IBGE (2011), Fundação Getúlio Vargas - FGV (2011) e dados da pesquisa.

Tabela 3. Resultados dos testes de raiz unitária DF-GLS` com e sem tendência

\begin{tabular}{|c|c|c|c|c|c|c|}
\hline \multirow{2}{*}{ Variável } & \multirow{2}{*}{ Tendência } & \multirow{2}{*}{ Lags } & \multirow{2}{*}{ Estatística $\mathbf{t}$} & \multicolumn{3}{|c|}{ Valores críticos } \\
\hline & & & & $1 \%$ & $5 \%$ & $10 \%$ \\
\hline \multirow{2}{*}{ Horas trabalhadas } & Não & 1 & -2.0470 & $-2,63$ & $-1,95$ & $-1,62$ \\
\hline & Sim & 3 & -3.6966 & $-3,77$ & $-3,19$ & $-2,89$ \\
\hline \multirow{2}{*}{ Capital } & Não & 1 & -1.2492 & $-2,63$ & $-1,95$ & $-1,62$ \\
\hline & Sim & 1 & -2.1910 & $-3,77$ & $-3,19$ & $-2,89$ \\
\hline \multirow{2}{*}{ PTF } & Não & 4 & -1.2558 & $-2,63$ & $-1,95$ & $-1,62$ \\
\hline & Sim & 3 & -1.4118 & $-3,77$ & $-3,19$ & $-2,89$ \\
\hline \multirow{2}{*}{ Área colhida } & Não & 1 & -0.4377 & $-2,63$ & $-1,95$ & $-1,62$ \\
\hline & Sim & 1 & -1.8074 & $-3,77$ & $-3,19$ & $-2,89$ \\
\hline \multirow{2}{*}{ Produto } & Não & 4 & -0.3606 & $-2,63$ & $-1,95$ & $-1,62$ \\
\hline & Sim & 1 & -2.0840 & $-3,77$ & $-3,19$ & $-2,89$ \\
\hline
\end{tabular}

Fonte: Resultados da pesquisa.

Os testes DF-GLS foram empregados de duas formas: com inclusão de constante e tendência determinística e somente com a inclusão da constante. Os resultados indicaram que, para a variável número de horas trabalhadas, a hipótese nula de presença de raiz unitária é rejeitada a $1 \%$ de significância, porém, não é rejeitada a $5 \%$ ou $10 \%$. Desta forma, o resultado encontrado para as horas trabalhadas evidenciou que a série possui raiz unitária a $5 \%$ de significância em ambos os testes.
Para a série de estoque de capital, os testes indicaram que a hipótese nula de presença de raiz unitária não é rejeitada a $1 \%, 5 \%$ ou a $10 \%$ de significância. Assim, o teste DF-GLS indicou que a série possui raiz unitária, ou não é estacionária.

Os testes DF-GLS, com e sem inclusão de tendência determinística, para a PTF, indicaram que a hipótese nula de presença de raiz unitária não pode ser rejeitada a $1 \%, 5 \%$ ou $10 \%$ de significância. Desta forma, os testes DF-GLS indicaram que a série de PTF possui raiz unitária. 
Tabela 4. Resultados dos testes de cointegração entre as variáveis PTF, horas trabalhadas na agricultura, capital agrícola, área colhida e produto agrícola

\begin{tabular}{cccc}
\hline $\begin{array}{c}\text { Hipótese } \\
\text { Nula }\end{array}$ & $\begin{array}{c}\text { Hipótese } \\
\text { Alternativa }\end{array}$ & $\lambda_{\text {traço }}$ & $\begin{array}{c}\text { Valores críticos de } \\
\text { Osterwald-Lenun (1992) }\end{array}$ \\
\hline $\mathrm{r}=0$ & $\mathrm{r}>0$ & 157,679 & 69,611 \\
$\mathrm{r} \leq 1$ & $\mathrm{r}>1$ & 78,861 & 47,707 \\
$\mathrm{r} \leq 2$ & $\mathrm{r}>2$ & 27,605 & 29,804 \\
$\mathrm{r} \leq 3$ & $\mathrm{r}>3$ & 6,461 & 15,408 \\
$\mathrm{r} \leq 4$ & $\mathrm{r}>4$ & 1,059 & 3,841 \\
\hline
\end{tabular}

Fonte: Resultados da pesquisa.

Na série de área colhida, a hipótese nula de presença de raiz unitária não pode ser rejeitada a $1 \%, 5 \%$ ou $10 \%$ de significância para os testes com e sem inclusão de tendência. O teste DF-GLS indicou, portanto, que a série de PTF possui raiz unitária ou não é estacionária.

Para o produto, a hipótese nula de presença de raiz unitária não pode ser rejeitada a 1\%, 5\% e $10 \%$ de significância com ou sem inclusão de tendência. Desta forma, o teste DF-GLS também indicou que a série de PTF possui raiz unitária.

Assim, os resultados obtidos nos testes indicaram a necessidade da inclusão de todas as variáveis em diferença no modelo.

Existe a necessidade de se definir o número de defasagens do modelo VAR estrutural. Para tanto, foram empregados testes AIC e SBC para o número de defasagens do sistema VAR, que apontaram que o melhor modelo é o de uma defasagem ${ }^{11}$.

O fato de as variáveis serem integradas de mesma ordem levou à necessidade de se testar a existência de cointegração entre elas e da adição de um termo de correção de erros no modelo VAR estrutural proposto. Com este objetivo, o procedimento de Johansen (1988) foi empregado para o cálculo da estatística $\lambda_{\text {traço }}$. Os valores críticos para os testes são aqueles apresentados por Osterwald-Lenun (1992).

11. Mesmo que os testes tivessem indicado a necessidade de um número maior de defasagens, devido à utilização de um modelo com dados anuais e do limitado número de observações, não seria possível a inclusão de um número de defasagens elevado.
Conforme pode ser observado na Tabela 4, a hipótese de não haver cointegração $(r=0)$ é rejeitada ao nível de significância de $5 \%$, pois a estatística $\lambda_{\text {traço }}$ possui valor de 157,7 , que é superior ao valor crítico de 69,6 .

A hipótese de $r \leq 1$ vetores cointegrantes também é rejeitada a $5 \%$ de significância, uma vez que a estatística $\lambda_{\text {traço }}$ possui valor superior ao crítico $(78,9$ e 47,7$)$, conforme pode ser visto na Tabela 4.

A hipótese de que existem $r \leq 2$ vetores de cointegração não pode ser rejeitada. Conforme observado na Tabela 4, o valor encontrado para a estatística $\lambda_{\text {traço }}$ foi de 27,6 , que é inferior ao valor crítico de Osterwald-Lenun (1992) a 5\% de significância, que é de 29,8 .

Desta forma, o teste $\lambda_{\text {traço }}$ indicou a necessidade da inclusão de dois vetores de cointegração no modelo VAR estrutural.

$\mathrm{Na}$ Tabela 5 são apresentados os resultados da matriz $\mathrm{A}_{0}$. As relações contemporâneas apresentaram os sinais esperados. As variáveis horas trabalhadas, capital, área colhida e PTF têm impactos contemporâneos positivos sobre o produto, isto é, um aumento nas variáveis gera, em maior ou menor proporção, uma elevação no produto agrícola no mesmo momento em que aqueles acontecem.

Conforme a Tabela 6, a decomposição da variância do produto agrícola é explicada em pouco menos de $70 \%$ por variações na PTF, em aproximadamente $17 \%$ pela área colhida e em cerca de $7 \%$ pela variação de capital na agricultura. A variável horas trabalhadas demonstrou baixo poder explicativo na decomposição dos erros de 
Tabela 5. Coeficientes, erro padrão, estatística te significância do modelo

\begin{tabular}{ccccc}
\hline Variável & Coeficiente & Erro padrão & Estatística t & Significância \\
\hline $\mathrm{a}_{51}$ & 0,517 & 0,023 & 22,045 & 0,000 \\
$\mathrm{a}_{52}$ & 0,108 & 0,061 & 1,774 & 0,076 \\
$\mathrm{a}_{53}$ & 0,773 & 0,117 & 6,606 & 0,000 \\
$\mathrm{a}_{54}$ & 0,504 & 0,052 & 9,669 & 0,000 \\
\hline
\end{tabular}

Fonte: Resultados da pesquisa.

Tabela 6. Decomposição da variância dos erros de previsão do produto agrícola

\begin{tabular}{ccccccc}
\hline Período & Erro padrão & PTF & Horas trabalhadas & Capital & Área colhida & Produto agrícola \\
\hline 1 & 0,064 & 71,25 & 0,55 & 7,80 & 16,10 & 4,30 \\
2 & 0,069 & 72,58 & 1,85 & 6,80 & 14,64 & 4,12 \\
3 & 0,071 & 70,55 & 2,87 & 6,62 & 16,00 & 3,95 \\
4 & 0,071 & 69,57 & 3,05 & 6,59 & 16,91 & 3,88 \\
5 & 0,072 & 69,25 & 3,08 & 6,60 & 17,22 & 3,86 \\
6 & 0,072 & 69,17 & 3,08 & 6,60 & 17,30 & 3,86 \\
7 & 0,072 & 69,15 & 3,08 & 6,60 & 17,32 & 3,86 \\
8 & 0,072 & 69,14 & 3,08 & 6,60 & 17,32 & 3,86 \\
9 & 0,072 & 69,14 & 3,08 & 6,60 & 17,32 & 3,86 \\
10 & 0,072 & 69,14 & 3,08 & 6,60 & 17,32 & 3,86 \\
\hline
\end{tabular}

Fonte: Resultados da pesquisa.

previsão, com pouco mais de 3\% do total. Estes resultados demonstram a importância da produtividade na dinâmica do produto agrícola, devido à grande parte da variação do produto explicada por esta variável.

A Figura 4 apresenta os efeitos dos choques acumulados da PTF sobre o produto agrícola, as horas trabalhadas, o capital e a área colhida.

Os choques são apresentados na forma de elasticidade; portanto, um choque inicial de PTF de $10 \%$ gera, ao final do período, uma elevação do capital da ordem de 1,1\%, sugerindo que, para que haja incorporação de novas tecnologias ao processo produtivo, faz-se necessário investimento para elevar o estoque de capital.

O impacto de um choque de PTF de $10 \%$ eleva em $0,3 \%$ a área colhida no segundo período e em $0,7 \%$ no final do período. Este resultado sugere que os aumentos de produtividade devido às inovações tecnológicas ocorridas no período tiveram influência positiva sobre a área plantada, contribuindo, desta forma, para a expansão da fronteira agrícola.

Para as horas trabalhadas, um aumento de $10 \%$ na PTF gera redução de $0,2 \%$ ao final do período. Este resultado sugere que as inovações tecnológicas incorporadas pela agricultura brasileira ao longo do período em análise foram levemente poupadoras de mão de obra. Desta forma, o processo de modernização da agricultura ocorrido nas décadas de 1970 e 1980 foi acompanhado de expressiva expansão da produção, porém, a utilização do fator trabalho experimentou oscilação negativa, apresentando resultado final um pouco inferior ao do início do período.

Conforme a Figura 4, um choque de PTF de $10 \%$ eleva em $2,9 \%$ o produto no segundo período e em $3,6 \%$ ao final do período, o que demonstra que os aumentos de produtividade estão diretamente relacionados a aumentos de produção. Em comparação aos impactos da PTF, os efeitos sobre as demais variáveis são relativamente pequenos.

Na Figura 5 são apresentados os efeitos dos choques acumulados das horas trabalhadas, capital, área colhida e PTF sobre o produto agrícola e do produto agrícola sobre si mesmo. Um choque de $10 \%$ na área colhida gera um impacto inicial de $5,0 \%$ sobre o produto, estabilizando-se em $5,1 \%$ ao final do período. Um choque no capital de $10 \%$ gera um aumento no produto que é inicialmente de 7,7\%. Ao final do período, 
Figura 4. Efeitos dos choques acumulados de PTF sobre as horas trabalhadas, o capital, a área colhida e o produto agrícola e da PTF sobre ela mesma

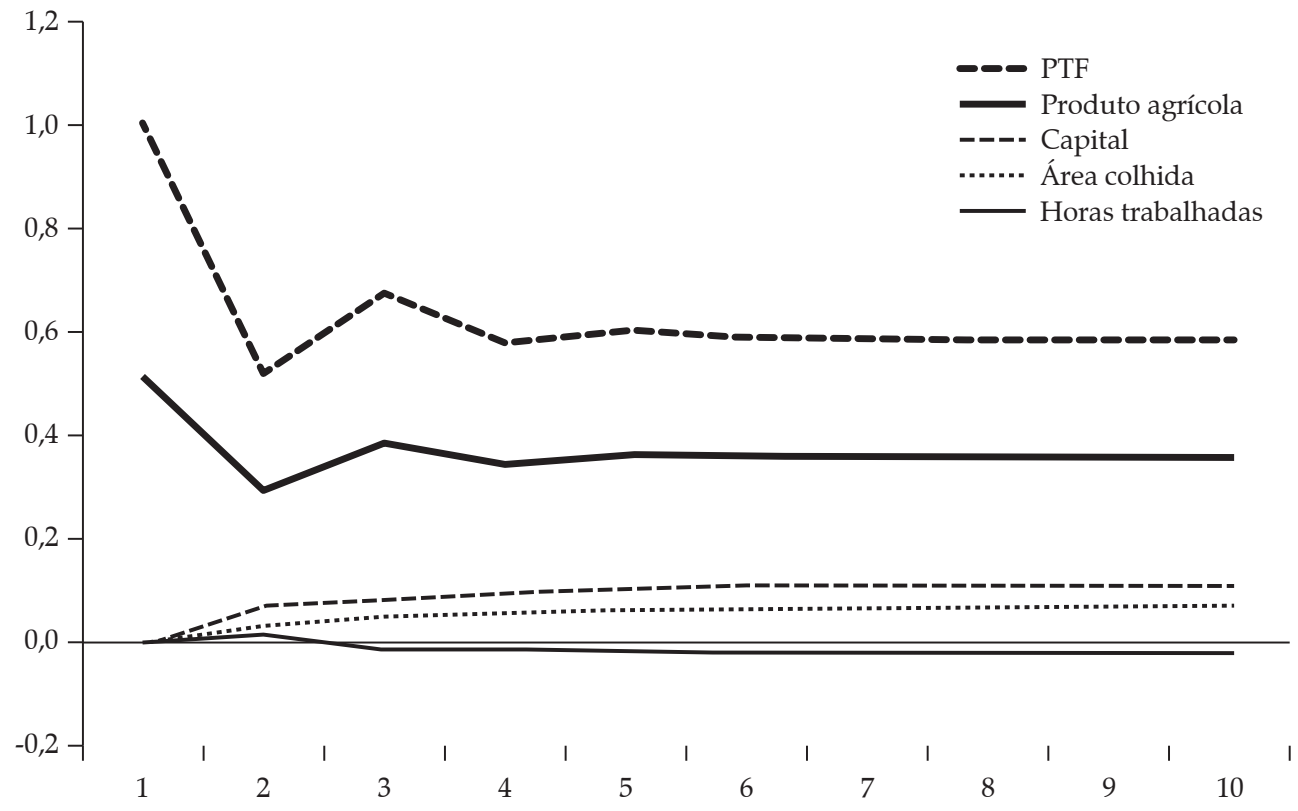

Fonte: Resultados da pesquisa.

Figura 5. Efeitos dos choques acumulados de horas trabalhadas, capital, área colhida e PTF sobre o produto agrícola e do produto agrícola sobre ele mesmo

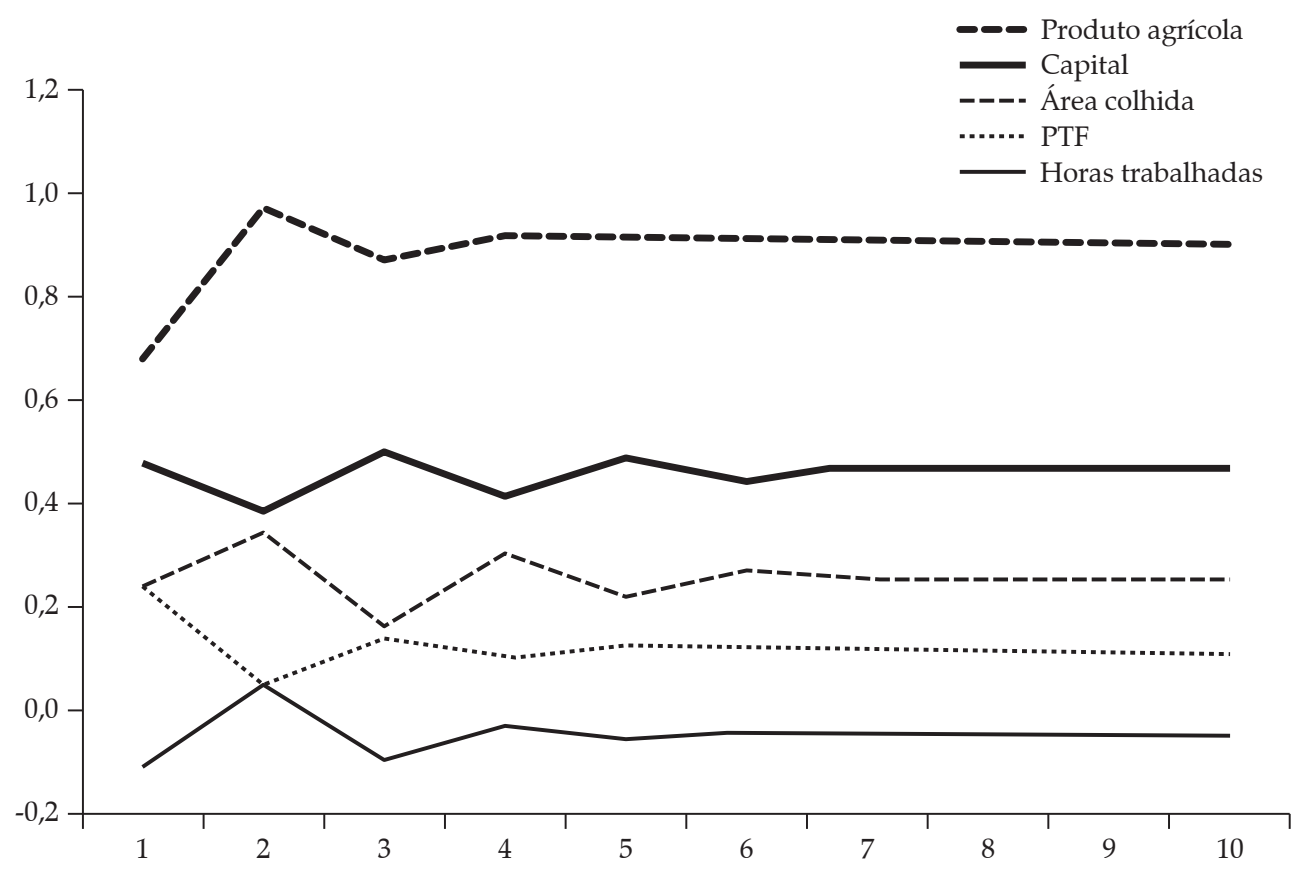

Fonte: Resultados da pesquisa. 
o choque inicial de capital de $10 \%$ gera sobre o produto um impacto semelhante, de $7,6 \%$. Um aumento do número de horas trabalhadas de $10 \%$ gera um choque inicial no produto de $1,1 \%$. Estes choques aumentam ao longo do período, gerando um impacto final da ordem de $1,8 \%$. Um choque de $10 \%$ da PTF sobre o produto agrícola gera um impacto inicial de $5,2 \%$, um impacto de $2,9 \%$ no segundo período, para depois estabilizar-se em torno de $3,6 \%$.
Conforme esperado, os resultados obtidos sugerem que todos os fatores de produção têm impacto positivo sobre o produto, isto é, elevações na utilização dos fatores aumentam o produto. Além disso, o impacto da PTF sobre o produto também é positivo, indicando que as inovações tecnológicas ocorridas no período contribuíram para a elevação do produto.

Na Tabela 7 é apresentada a contribuição de cada variável na decomposição histórica da vari-

Tabela 7. Erro de previsão e contribuição percentual das variáveis na decomposição histórica da variância dos erros de previsão do produto (\%) - 1974 a 2009

\begin{tabular}{|c|c|c|c|c|c|c|}
\hline Ano & $\begin{array}{c}\text { Erro de } \\
\text { previsão }\end{array}$ & PTF & $\begin{array}{c}\text { Horas } \\
\text { Trabalhadas }\end{array}$ & Capital & $\begin{array}{c}\text { Área } \\
\text { colhida }\end{array}$ & $\begin{array}{l}\text { Produto } \\
\text { agrícola }\end{array}$ \\
\hline 1974 & $-2,931$ & $-2,233$ & $-0,422$ & $-1,027$ & 0,018 & 0,724 \\
\hline 1975 & 6,302 & 4,753 & $-1,274$ & 2,419 & $-0,432$ & 0,795 \\
\hline 1976 & $-9,842$ & $-6,775$ & $-0,595$ & 2,227 & $-2,239$ & $-2,651$ \\
\hline 1977 & 0,325 & 2,798 & $-0,508$ & 1,281 & $-0,699$ & $-2,466$ \\
\hline 1978 & $-5,091$ & $-5,004$ & 1,168 & $-0,870$ & 0,926 & $-1,292$ \\
\hline 1979 & 2,056 & $-3,541$ & $-1,961$ & 2,943 & 5,926 & $-1,031$ \\
\hline 1980 & 5,868 & $-1,799$ & $-1,211$ & 4,283 & 3,906 & 0,713 \\
\hline 1981 & 8,756 & 12,406 & $-1,327$ & $-2,854$ & $-1,158$ & 2,117 \\
\hline 1982 & 2,086 & 2,580 & $-1,213$ & $-6,763$ & 5,272 & 2,637 \\
\hline 1983 & 3,386 & 10,106 & $-0,987$ & $-8,655$ & 1,475 & 2,309 \\
\hline 1984 & $-3,003$ & 2,608 & $-2,373$ & $-5,772$ & 0,021 & 2,740 \\
\hline 1985 & 17,656 & 11,855 & 2,294 & $-0,760$ & 0,109 & 3,502 \\
\hline 1986 & 7,902 & 1,303 & 0,766 & 1,373 & $-2,019$ & 6,420 \\
\hline 1987 & 7,157 & 2,355 & $-1,470$ & 2,450 & $-3,201$ & 7,142 \\
\hline 1988 & 8,809 & 4,424 & 0,188 & 1,899 & $-4,047$ & 6,370 \\
\hline 1989 & 11,489 & 8,823 & $-0,798$ & 0,674 & $-1,039$ & 3,660 \\
\hline 1990 & $-5,521$ & 0,088 & $-2,435$ & $-1,950$ & $-5,104$ & 3,982 \\
\hline 1991 & $-10,656$ & $-3,988$ & 0,624 & $-5,287$ & $-7,956$ & 6,080 \\
\hline 1992 & $-7,700$ & 3,634 & $-1,242$ & $-6,899$ & $-6,284$ & 3,361 \\
\hline 1993 & $-7,593$ & 3,738 & 1,150 & $-3,618$ & $-10,576$ & 2,176 \\
\hline 1994 & $-3,844$ & 3,890 & 0,162 & 2,505 & $-11,740$ & 2,140 \\
\hline 1995 & $-7,093$ & 2,875 & 1,508 & $-3,402$ & $-9,449$ & 1,714 \\
\hline 1996 & $-17,129$ & $-0,701$ & 2,170 & $-5,821$ & $-13,633$ & 0,423 \\
\hline 1997 & $-13,102$ & 4,608 & 0,938 & $-3,803$ & $-13,500$ & $-1,096$ \\
\hline 1998 & $-10,627$ & 4,954 & 1,099 & $-5,569$ & $-11,026$ & 0,249 \\
\hline 1999 & $-14,021$ & 1,382 & 1,144 & $-6,419$ & $-10,872$ & 0,530 \\
\hline 2000 & $-12,178$ & $-1,008$ & 1,880 & $-5,094$ & $-9,049$ & 0,883 \\
\hline 2001 & $-9,634$ & 2,640 & $-0,916$ & $-6,091$ & $-8,621$ & 3,547 \\
\hline 2002 & $-13,457$ & $-3,369$ & $-0,030$ & $-6,843$ & $-7,411$ & 3,865 \\
\hline 2003 & $-3,885$ & 0,722 & 0,716 & $-5,887$ & $-4,151$ & 5,034 \\
\hline 2004 & $-3,615$ & $-2,994$ & 2,025 & $-5,147$ & $-1,803$ & 4,558 \\
\hline 2005 & $-5,147$ & $-3,562$ & 3,638 & $-8,004$ & $-0,178$ & 3,344 \\
\hline 2006 & $-3,258$ & $-1,213$ & 1,624 & $-7,618$ & 1,305 & 2,967 \\
\hline 2007 & 1,770 & 0,973 & 0,984 & $-4,014$ & 0,460 & 3,505 \\
\hline 2008 & $-2,017$ & $-2,239$ & 0,130 & $-2,179$ & 0,552 & 1,766 \\
\hline 2009 & 1,157 & 1,280 & $-0,195$ & $-0,070$ & 0,074 & 0,070 \\
\hline
\end{tabular}

Fonte: Resultados da pesquisa. 
ância dos erros de previsão para o período compreendido entre 1974 e 2009.

Durante as décadas de 1970 e 1980, os erros de previsão do produto foram, na maior parte das vezes, positivos, o que indica que o produto observado para a agricultura no período esteve acima do previsto pelo modelo. A partir da decomposição dos erros - em termos das previsões decorrentes de considerar apenas um dos fatores explicativos de cada vez -, poderão ser definidos quais deles contribuíram para o erro observado. Conforme pode ser observado na Figura 6 e na Tabela 7, as variáveis PTF, capital e terra foram mais influentes no comportamento não antecipado do produto. A variável PTF trouxe a maior contribuição na decomposição histórica da variância dos erros de previsão no período: os erros de previsão do produto advindos da consideração de variações apenas na PTF seguem de perto (em magnitude e direção) os erros de previsão do produto considerando a totalidade de variáveis do modelo. Desta forma, a inovação tecnológica foi a variável que mais contribuiu para que o produto crescesse acima do nível esperado.

Para as décadas de 1990 e 2000, os erros de previsão associadas unicamente à PTF continuaram contribuindo para erros positivos do produto; porém, o produto passou a ficar abaixo do previsto, agora por força dos erros de previsão associados tanto ao capital e, mais marcantemente, à terra (especialmente nos anos 1990, quando a área colhida caiu). Estes resultados podem ser observados na Figura 7 e na Tabela 7. Assim, o crescimento dos investimentos e a expansão da fronteira agrícola se deram abaixo do previsto, reduzindo os erros de previsão do produto.

A variável número de horas trabalhadas na agricultura teve pouco impacto sobre os erros de previsão do produto. O trabalho foi mais relevante durante a década de 1980, quando variou de forma mais acentuada: aumentou na primeira metade e caiu na segunda.

Figura 6. Contribuição percentual da PTF na decomposição histórica da variância dos erros de previsão do produto e erro de previsão do produto - 1974 a 2009

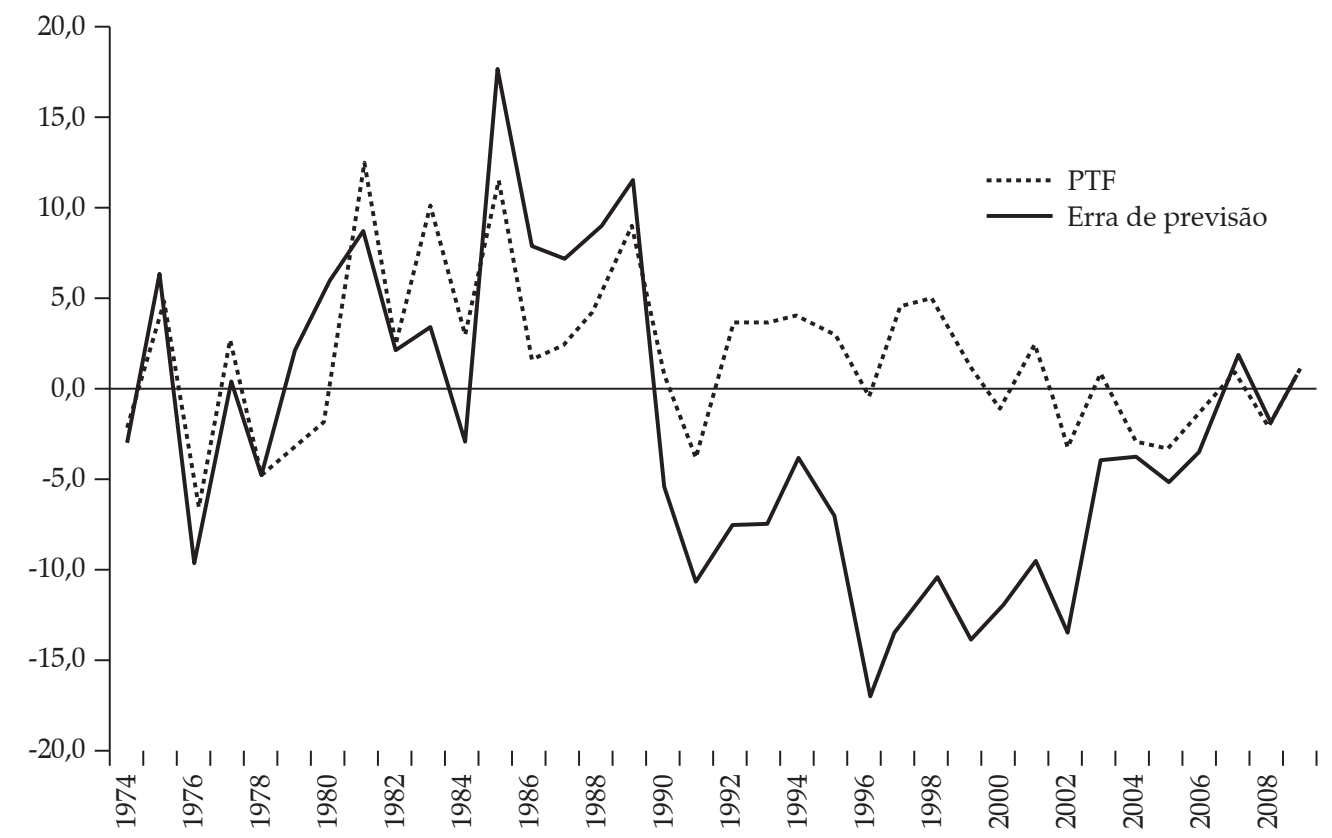

Fonte: Resultados da pesquisa. 
Figura 7. Contribuição percentual do capital e da área plantada na decomposição histórica da variância dos erros de previsão do produto e erro de previsão do produto - 1974 a 2009

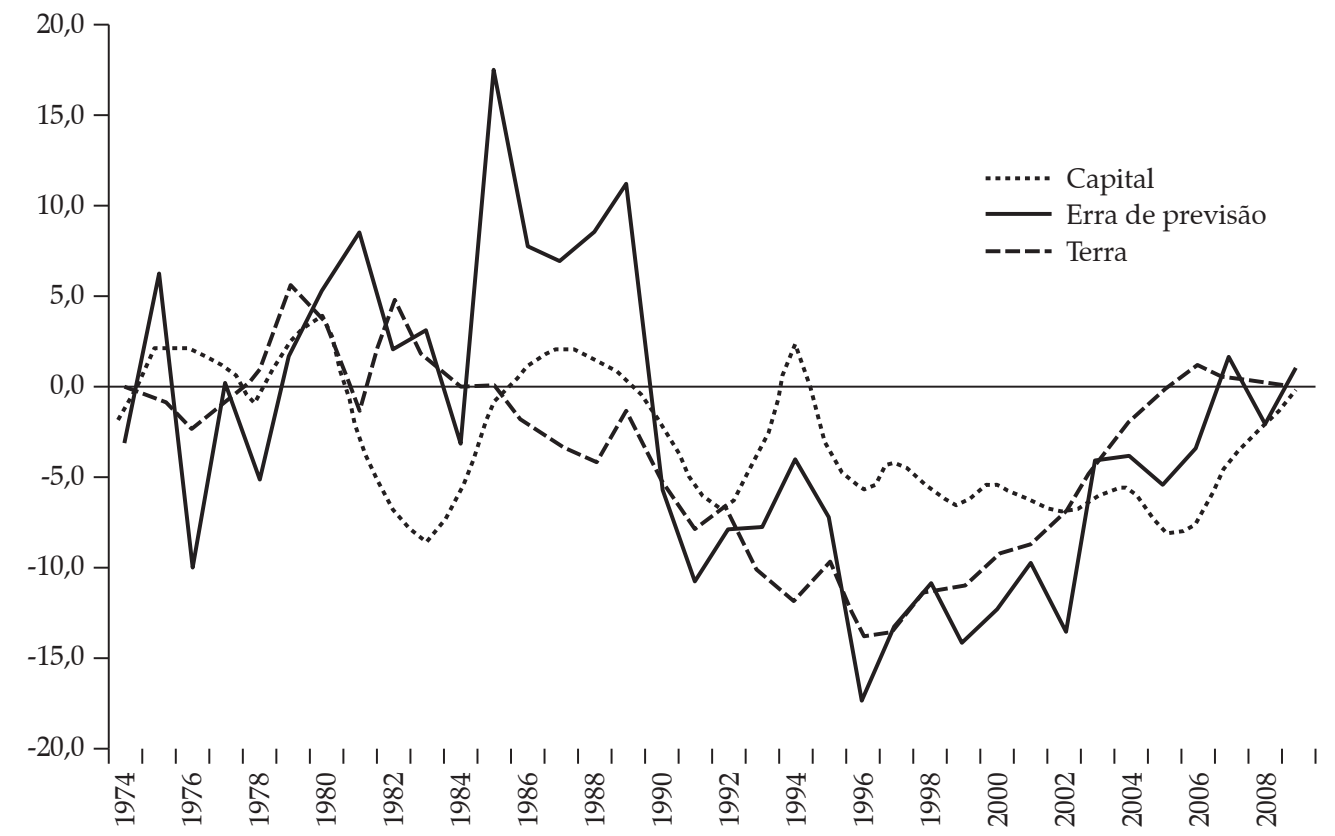

Fonte: Resultados da pesquisa.

Os choques próprios do produto, que representam os impactos que não estão relacionados aos fatores de produção ou à PTF tiveram pouca influência sobre os erros de previsão do produto, a exemplo dos choques no trabalho. Na maior parte das vezes, contribuíram para elevar o crescimento do produto além do esperado.

\section{Conclusão}

Este artigo teve por objetivo analisar os impactos dinâmicos dos fatores de produção capital, trabalho e terras, bem como da PTF no produto agrícola, simulando uma função de produção para o setor agrícola, fazendo uso de uma estratégia empírica baseada em um modelo econométrico VAR estrutural.

Essa análise VAR indicou que a PTF é o fator que tem maior potencial para aumentar o produto agrícola, contribuindo de forma marcante para explicar a variância dos erros de previsão. À luz do modelo proposto, os demais fatores apresentam menor impacto no produto.

Os resultados referentes às análises de impulso-resposta demonstraram que um aumento da quantidade de cada um dos fatores de produção empregados geraria impactos positivos, porém, de diferentes magnitudes sobre o produto agrícola, sendo que, dentre os fatores considerados, o que tem maior influência sobre o produto é o capital.

Um aumento na PTF gera leve redução no trabalho agrícola. Este resultado sugere que a modernização da agricultura ocorrida no período em análise trouxe inovações tecnológicas que não contribuíram para o aumento no emprego de mão de obra na agricultura brasileira.

O modelo evidenciou que elevações na PTF geraram aumento na área plantada e no emprego do capital. A PTF teria, portanto, o condão de aumentar a taxa de retorno nesses investimentos. Este resultado sugere que a modernização da agricultura ocorrida no período, com elevação da 
produtividade, exerceu influência sobre a expansão da fronteira agrícola, permitindo a exploração de novas áreas.

A decomposição histórica da variância dos erros de previsão do produto agrícola indicou que, durante as décadas de 1970 e 1980, os aumentos não antecipados dessa variável podem ser explicados em grande parte pela evolução da PTF. Na década de 1990, embora a produtividade continuasse a elevar o potencial de crescimento do produto, a desaceleração nos investimentos e na expansão da área cultivada predominaram no desempenho do produto. Quanto ao papel da área cultivada, pode ter predominado, numa primeira etapa, o fato de que novas áreas podiam ser incorporadas em virtude dos avanços tecnológicos. Numa segunda etapa, a preocupação ambiental e as práticas conservacionistas conjugaram-se para diminuir o papel da área no crescimento do produto agrícola. Além disso, o aproveitamento de novas terras só é possível na presença de novos investimentos que, por sua vez, foram escassos no final da década de 1990 e início dos anos 2000. Mais recentemente, já ao longo dos anos 2000, capital e terra apresentam uma tendência de reversão nos seus efeitos no produto, provavelmente devido à maior alocação de crédito para o setor.

O presente trabalho realizou uma análise agregada para a economia agrícola brasileira. Para trabalhos futuros, um estudo mais desagregado poderia ser feito, visando captar os efeitos descritos por região. Por fim, cabe salientar que, neste artigo, o efeito preço foi isolado do modelo proposto, tanto no que tange o produto quanto os insumos. Portanto, a inter-relação entre preços e PTF não é analisada. Esta inter-relação também poderia ser objeto de estudos futuros. Neste sentido, cabe ressaltar que o mercado internacional tem tido impacto crescente na economia agrícola brasileira, especialmente a partir de 2005. Este choque no mercado internacional de commodities pode ter tido efeito sobre a produtividade da agricultura. Assim, novas análises poderiam ser realizadas no futuro para fornecer informações sobre este tema.

\section{Referências bibliográficas}

ALVES, A. F. e ARAÚJO, P. F. C. Investimentos na agricultura brasileira: estimações alternativas de 1980 a 1998. Revista de Economia e Sociologia Rural, Brasília, v. 40, n. 4, p. 755-768, 2002. Disponível em: <http:// www.scielo.br/scielo.php?script $=$ sci_arttext\&pid $=$ S0103-20032002000400001>. Acesso em: 22 nov. 2011.

ANDERSON, K. Agricultural Policies: Past, Present, and Prospective under Doha. In: KARAPINAR, B. e HÄBERLI, C. (Ed.) Food Crises and the WTO. Cambridge and New York: Cambridge University Press, 2010. p. 167-186.

BARROS, A. L. M. Capital, produtividade e crescimento na agricultura: o Brasil de 1970-1995. Piracicaba. 1999. 149 p. Tese de doutorado (Doutorado em Economia Aplicada) - Escola Superior de Agricultura "Luiz de Queiroz", Universidade de São Paulo, Piracicaba, 1999.

BARROS, G. S. C. Investimento em tratores agrícolas no Brasil. Piracicaba. 1981. 200 p. Tese (Livre-docência) - Escola Superior de Agricultura "Luiz de Queiroz", Universidade de São Paulo, Piracicaba, 1981.

BARROS, G. S. C. Impacts of monetary and real factors on the US dollar in the identifiable VAR models. Revista Brasileira de Economia, Rio de Janeiro, v. 45, n. 4, p. 519541, 1991. Disponível em: < http://bibliotecadigital.fgv. br/ojs/index.php/rbe/article/viewArticle/535>. Acesso em: 10 dez. 2011.

BARROS, J. R. M. Política e desenvolvimento agrícola no Brasil. In: VEIGA, A. (Ed.). Ensaios sobre política agrícola. São Paulo: Secretaria da Agricultura, 1979. p. 9-35.

BARROS, J. R. M., PASTORE, A. C. e RIZZIERI, J. A. Evolução recente da agricultura mineira. In: BARROS, J. R. M. e GRAHAM, D. (Ed.). Estudos sobre a modernização da agricultura brasileira. São Paulo: Instituto de Pesquisas Econômicas da Universidade de São Paulo, 1977.

BARROS, J. R. M. Política e desenvolvimento agrícola no Brasil. São Paulo: Instituto de Pesquisas Econômicas da Universidade de São Paulo, 1982, 36p. (IPE/USP, Texto para discussão, 16/82).

BONELLI, R. e FONSECA, R. Ganhos de produtividade ede eficiência: novos resultados para a economia brasileira. Rio de Janeiro: Instituto de Pesquisa Econômica Aplicada, 1998. 43p. (IPEA Texto para Discussão, 557). Disponível em: <http://www.ipea.gov.br/ agencia/ images/stories/PDFs/TDs/td_0557.pdf > . Acesso em: 19 nov. 2011. 
BRAGAGNOLO, C., SPOLADOR, H. F. S. e BARROS, G. S. C. Regional Brazilian agriculture TFP analysis: a stochastic frontier analysis approach. Revista Economia, Selecta, Brasília, v. 11, n. 4, 2012.

BRANDÃO, A. S. P., REZENDE, G. C. e MARQUES, R. W. C. Crescimento agrícola no período 1999/2004: explosão da área plantada com soja e meio ambiente no Brasil. Disponível em: <http://www.econ.puc-rio.br/pdf/ seminario/2005/gervasio\%20rezende.pdf $>$. Acesso em: 15 ago. 2011.

CANOVA, F. Methods for applied macroeconomic research. 1. ed. Princeton e Oxford: Princeton University Press, 2007. $492 \mathrm{p}$.

ELLIOTT, G., ROTHENBERG, T. J. e STOCK, J. H. Efficient tests for an autoregressive unit root. Econometrica, Chicago, v. 64, n. 4, p. 813-836, 1996.

ENDERS, W. Applied econometric time series. 2. ed. New York: Willey, 2004. 460 p.

GASQUES, J. G., BASTOS, E. T., BACCHI, M. R. P. e CONCEIÇÃO, J. C. P. R. Condicionantes da produtividade da agropecuária brasileira. Brasília: Instituto de Pesquisa Econômica Aplicada, 2004. 34 p. (IPEA. Texto para discussão, 1017). Disponível em: < http://www.ipea. gov.br/portal/images/stories/PDFs/TDs/td_1017.pdf $>$. Acesso em: 30 ago. 2013.

GASQUES, J. G., BASTOS, E. T., BACCHI, M. R. P. e VALDES, C. Produtividade total dos fatores e transformações da agricultura brasileira: análise dos dados dos Censos Agropecuários. In: ENCONTRO NACIONAL DE ECONOMIA - ANPEC, 38, 2010, Salvador. Anais ..., 2010, Salvador: ANPEC. 1 CD-ROM.

JOHANSEN, S. Statistical analysis of cointegration vectors. Journal of Economic Dynamics and Control, London, v. 12, p. 231-254, jun/set. 1988.

JOHNSON, D. G. The nature of the supply function for agricultural products. American Economic Review, New York, v. 40, n. 4, p. 539-564, 1950.

JORGENSON, D. W. The development of a dual economy. Economic Journal, London, v. 71, n. 282, p. 309-334, 1961.
MELO, F. B. H. Agricultura brasileira nos anos 90: o real e o futuro. Economia Aplicada, São Paulo, v. 2, n. 1, p. 163-182, 1998.

MELO, F. B. H. A abertura comercial e o papel dos aumentos de produtividade na agricultura brasileira. Instituto Futuro Brasil - IFB, 2002.

MENDES, S. M., TEIXEIRA, E. C. e SALVATO, M. A. Investimentos em infra-estrutura e produtividade total dos fatores na agricultura brasileira: 1985-2004. Revista Brasileira de Econômia, Rio de Janeiro, v. 63, n. 2, p. 91-102, 2009. Disponível em: < http://www.scielo.br/ pdf/rbe/v63n2/02.pdf $>$. Acesso em: 12 nov. 2011.

OLIVEIRA, J. C. e MONTEZANO, R. M. S. Os Limites das fontes de financiamento da agricultura no Brasil. Estudos Econômicos, São Paulo, v. 12, n. 2, p. 139-159, 1982.

OSTERWALD-LENUM, M.A. A note with quantiles of the asymptotic distribution of the maximum likelihood cointegration rank test statistics. Oxford Bulletin of Economics and Statistics, Oxford, v. 53, n. 3, p. 461-472, 1992.

PFAFF. B. Analysis of integrated and cointegrated time series with R. New York: Springer, 2008. 188p.

PIRES, J. F. e GARCIA, J. F. Productivity of nations: a stochastic frontier approach to TFP decomposition. São Paulo: Fundação Getúlio Vargas, 2004. 40 p. (FGV. Texto para Discussão, 143). Disponível em: <http:// bibliotecadigital.fgv.br/dspace/handle/10438/1945>. Acesso em: 21 ago. 2011.

REZENDE, G. C. Políticas trabalhista, fundiária e de crédito agrícola no Brasil: uma avaliação crítica. Revista de Economia e Sociologia Rural, Piracicaba, v. 44, n.1, p. 47-78, 2006. Disponível em: <http://www.scielo.br/scielo. php? pid $=$ S0103-20032006000100003\&script $=$ sci arttext>. Acesso em: 30 maio 2012.

SANTOS, Z. A. P. de. Adoção tecnológica na agricultura paulista. São Paulo: Instituto de Pesquisas Econômicas da Universidade de São Paulo, 119 p, 1984.

SILVA, C. R. L. Inovação tecnológica e distribuição de renda: impacto distributivo dos ganhos de produtividade na agricultura brasileira. Coleção Estudos Agrícolas, São Paulo: Instituto de Economia Agrícola, n. 2, p. 13-245, 1995. 